\title{
The Role of Testing Technical Features of Concrete to Assess Predicted Durability of Massive Reinforced Concrete Structures on the Example of Turbine Set Foundations**
}

\section{Introduction}

In the mid-90s, in connection with the modernization of one of the power plants, the possibility of using two existing reinforced concrete framework foundations for new turbine sets was considered. It was necessary to answer the question whether, assuming similar loads, it was possible to count on a reliable use of the existing foundations throughout the anticipated period of their usability, i.e. for at least another 40 years.

The answer called for testing the technical condition of both foundations and checking the mechanical and physico-chemical properties of the concrete from which they were made.

The foundations were designed and constructed in the early 60 's of the twentieth century.

While the condition of the above-ground part did not raise any major objections, it was unknown in what condition are massive bottom plates, after about 40 years of their utilization, recessed below the basement floor. Already in the course of their construction, the issue was raised whether exothermic processes of setting and hardening of concrete did not lead to a reduction in its strength. The strength tests of the concrete of the foundation no. 2, conducted at the end of 1962 [1] showed large discrepancies of the results obtained both by the sclerometric non-destructive testing and the use ultrasonic flaw detector.

On the basis of the first ones it was found that the average former class of the concrete at the surface of the block was approximately $R_{w}=170 \mathrm{kG} / \mathrm{m}^{2}$, while the other ones indicated that it was not more than $120 \mathrm{kG} / \mathrm{m}^{2}$.

* AGH University of Science and Technology, Faculty of Mining Surveying and Environmental Engineering, Krakow, Poland

** This article was prepared within the scope of the AGH statutory research no. 11.11.150.005 
In order to predict further life of the reinforced concrete bottom plates of turbine unit foundations, their technical condition was assessed (visual inspection of the exposed concrete surfaces) and a detailed study of the technical properties of the concrete was carried out, including [2]:

- assessment of compressive strength, based on destructive testing of the collected core samples,

- specification of strength distributions based on non-destructive testing,

- determination of static elastic modulus,

- determination of mass absorbability,

- determination of bulk density,

- determination of carbonation depth,

- specification of the binder content,

- determination of the content of ions,

- indication of changes in the phase composition and morphology of cement paste and concrete,

- assessment of the severity of corrosion of reinforcing steel.

The paper presents methods for the implementation of the above studies and summarizes their results, which were the basis for determining the technical condition of the bottom plates and for predicting a further period of their use. Moreover, an assessment of the accuracy of the conclusions formulated on the basis of periodic technical inspections of these foundations was made.

\section{Description of the Foundation Structure}

The studied foundations were designed as twin reinforced concrete structures (Fig. 1) of a spatial frame construction, made up of six single-span transverse frames and two four-span longitudinal frames [3]. The load of the frame foundation was transferred to the substrate through the bottom plate.

The dimensions of its horizontal projection were as follows:

- length $31.92 \mathrm{~m}$,

- width $9.50 \mathrm{~m}$,

- height $2.00 \mathrm{~m}$.

The plate was at a depth of $5.0 \mathrm{~m}$ below ground level, on a 20-centimeter-thick layer of lean concrete and a damp proof layer. The vertical walls of the bottom plate were insulated against moisture.

According to the preserved project documentation $[1,2]$ as well as the conducted studies [3], Portland cement 350 from "Chełm Lubelski" Cement Plant was used to produce concrete, in a relatively large amount (from 450 to $513 \mathrm{~kg} / \mathrm{m}^{3}$ ). The chemical composition of the cement used has been presented in Table 1 . The documentation assumed to obtain concrete of the former class $R_{w}=200 \mathrm{kG} / \mathrm{m}^{2}$. The foundation was reinforced with carbon steel of standard quality of St0 type. 

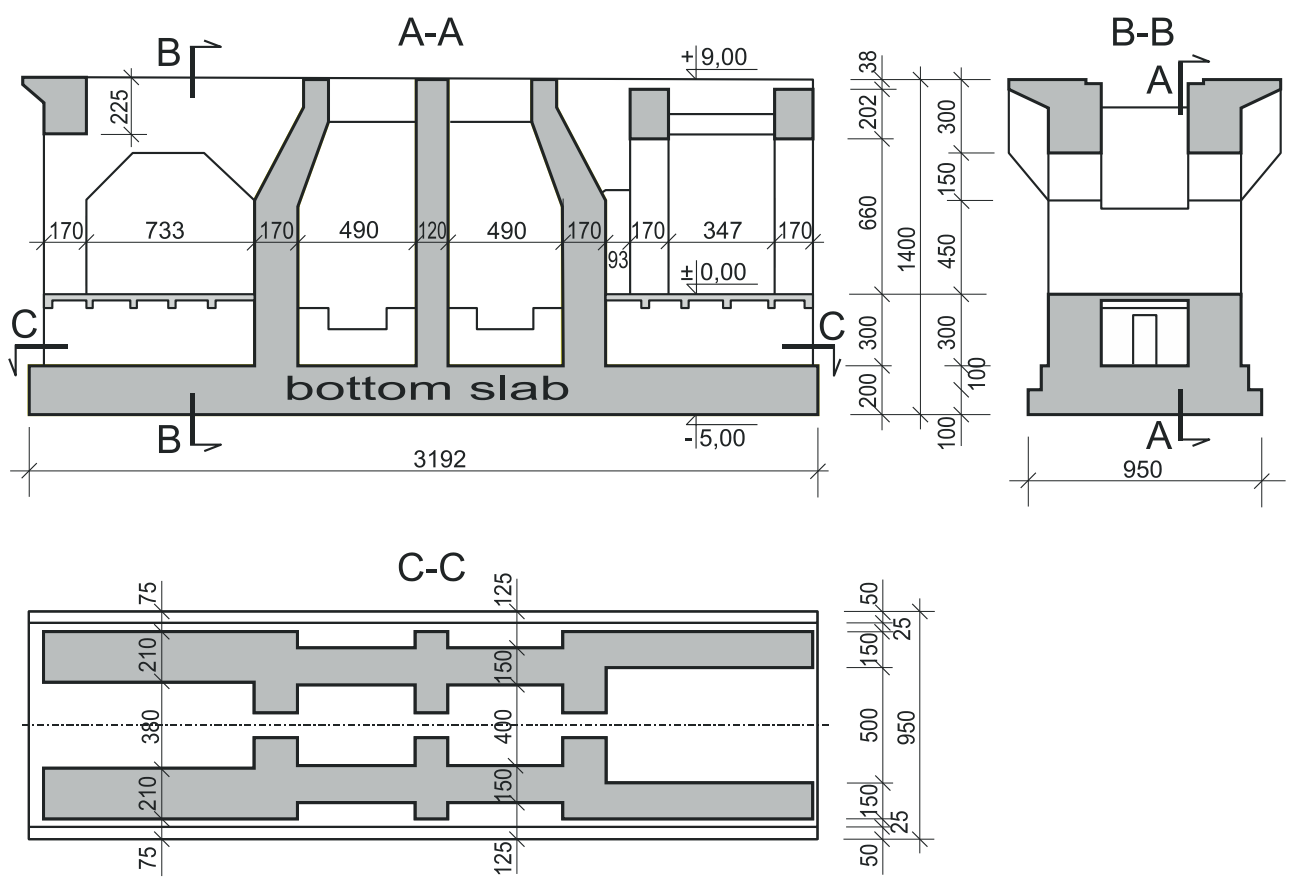

Fig. 1. Supporting structure geometry of the foundation no. 2

Source: [2]

Table 1. Characteristics of Portland cement 350 used to make the studied foundations

\begin{tabular}{|c|c|c|c||}
\hline \multicolumn{2}{|c|}{ Chemical composition [\%] } & \multicolumn{2}{c|}{ Modules } \\
\hline \hline $\mathrm{CaO}$ & 67.73 & Kind & 0.92 \\
\hline $\mathrm{MgO}$ & 0.90 & $\mathrm{MK}$ & 2.91 \\
\hline $\mathrm{SiO}_{2}$ & 22.27 & $\mathrm{MG}$ & 1.82 \\
\hline $\mathrm{Al}_{2} \mathrm{O}_{3}$ & 4.94 & $\mathrm{MH}$ & 2.25 \\
\hline $\mathrm{Fe}_{2} \mathrm{O}_{3}$ & 2.73 & Computational mineralogical composition [\%] \\
\hline $\mathrm{SiO}_{3}$ & 0.55 & $\mathrm{C}_{3} \mathrm{~S}$ & 66.96 \\
\hline $\mathrm{CaO}_{n}$ & 0.96 & $\mathrm{C}_{2} \mathrm{~S}$ & 13.72 \\
\hline Insoluble matter & 0.19 & $\mathrm{C}_{3} \mathrm{~A}$ & 8.69 \\
\hline Ignition loss & 0.10 & $\mathrm{C}_{4} \mathrm{AF}$ & 8.10 \\
\hline
\end{tabular}

Source: $[2,3]$ 


\section{Concrete Cores for Laboratory Tests}

To collect concrete cores, drilling machine Hilti DCM-1.5 was used, equipped with core diamond drill bits, having a diameter of $\phi=108 \mathrm{~mm}$, with water cooling. The location of the places where the cores were collected from are shown in Figure 2. In the case of the side walls of the bottom plate, the cores were drilled horizontally (Fig. 3), and the others were drilled vertically downwards. Each core was assigned a number corresponding to the place from which it was collected, as marked in the figure. In total, 7 cores were collected from the foundation no. 1, and as many as 11 cores from the foundation no. 2.
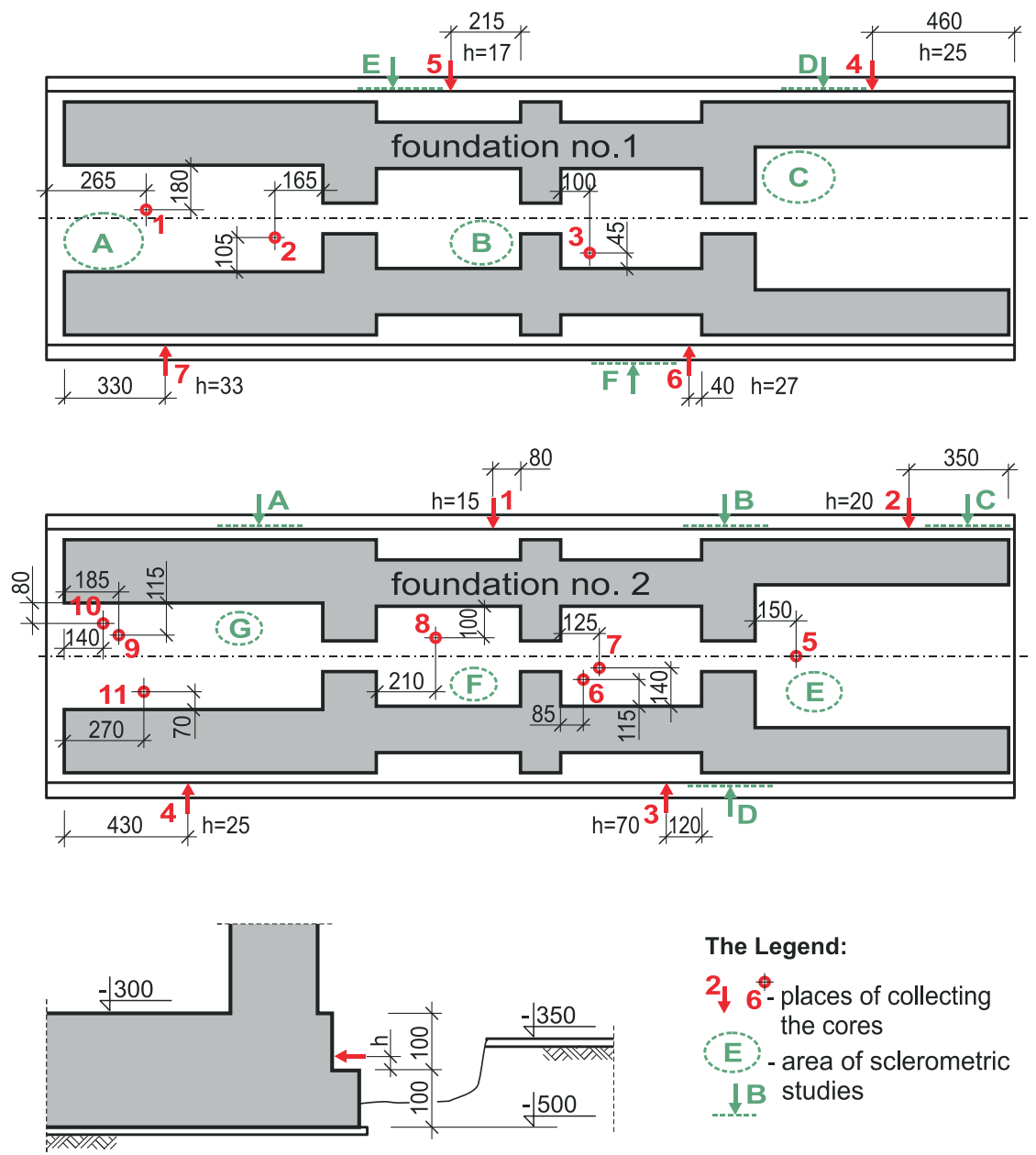

The Legend:

$2 \downarrow 6$ - places of collecting the cores

E - area of sclerometric

$\downarrow B$ studies

Fig. 2. Location of the places of collecting the concrete cores, and the areas of the sclerometric studies of the bottom plates of foundations no. 1 and 2 


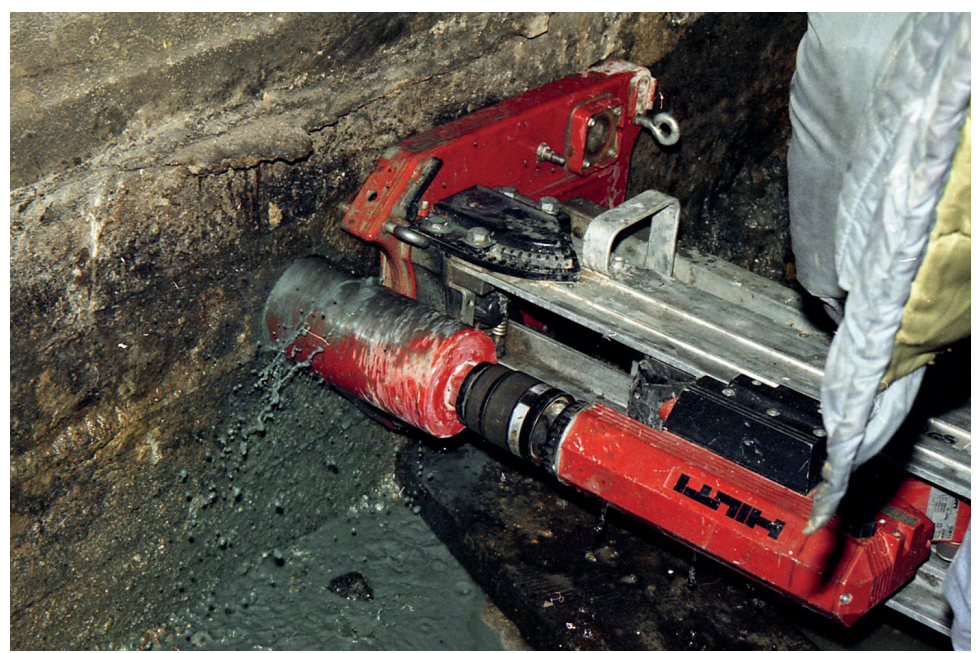

Fig. 3. Drilling the core no. 7 from the bottom plate of the foundation no. 1 Source: [3]

The cores were cut into three types of samples (Fig. 4), and so [3]:

- samples for chemical tests from both ends of each core and from the middle part, with a height of about $10-60 \mathrm{~mm}$,

- samples for testing compressive strength, with a height (length) of approximately equal to their diameter,

- samples for testing the elastic modulus of the concrete, with a height equal to twice their diameter.

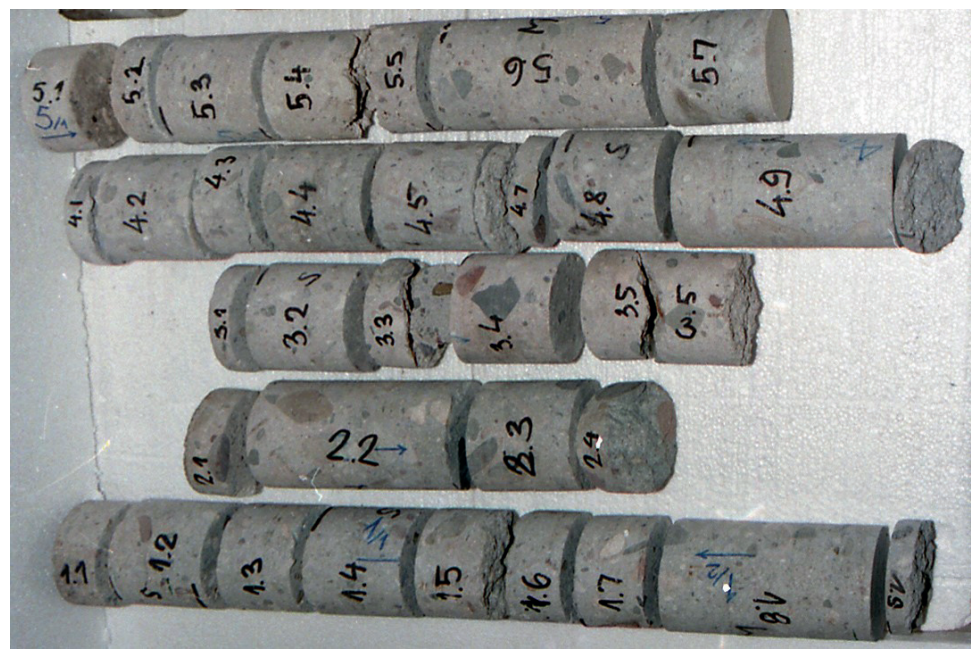

Fig. 4. The cores from the bottom plate of the foundation no. 1 cut into samples 


\section{Laboratory Test Results}

Table 2 summarizes the results of laboratory tests of the concrete cores collected from the bottom plates of both of the analyzed foundations, of the scope stated in Section 1. These studies were carried out in the years 1995-1996, in accordance with the then applicable standard PN-88/B-06250 [4].

Table 2. Test results of the concrete cores collected from the bottom plates of the foundations no. 1 and 2

\begin{tabular}{|c|c|c|c|c|}
\hline & \multirow{2}{*}{\multicolumn{2}{|c|}{ Type of tests }} & \multicolumn{2}{|c|}{ Foundation } \\
\hline & & & \multirow{2}{*}{$\frac{\text { no. } 1}{28.8}$} & \multirow{2}{*}{$\frac{\text { no. } 2}{36.0}$} \\
\hline \multirow{5}{*}{$\begin{array}{l}\text { Study of the } \\
\text { mechanical } \\
\text { properties }\end{array}$} & \multicolumn{2}{|l|}{ average strength $\bar{R}[\mathrm{MPa}]$} & & \\
\hline & \multicolumn{2}{|c|}{ guaranteed durability $R_{B}^{G}[\mathrm{MPa}]$} & 19.6 & 27.6 \\
\hline & \multicolumn{2}{|c|}{ standard deviation $S_{R}[\mathrm{MPa}]$} & 5.6 & 5.12 \\
\hline & \multicolumn{2}{|l|}{ index of variation $Z_{R}[\%]$} & 19.4 & 14.2 \\
\hline & \multicolumn{2}{|c|}{ static elastic modulus $E_{b}[\mathrm{MPa}]$} & 21000 & 28500 \\
\hline \multirow{4}{*}{$\begin{array}{l}\text { Study of } \\
\text { the physical } \\
\text { properties }\end{array}$} & \multirow{2}{*}{ bulk density $\rho_{o}\left[\mathrm{~kg} / \mathrm{dcm}^{3}\right]$} & on average & 2248 & 2000 \\
\hline & & from - to & $2214-2272$ & $1869-2131$ \\
\hline & \multirow{2}{*}{ mass absorbability $n_{w}[\%]$} & on average & 4.78 & 10.3 \\
\hline & & from - to & $3.5-6.4$ & $8.7-12.3$ \\
\hline \multirow{2}{*}{$\begin{array}{l}\text { Analysis of } \\
\text { the concrete } \\
\text { composition }\end{array}$} & \multicolumn{2}{|c|}{ aggregate content in the concrete $\left[\mathrm{Mg} / \mathrm{m}^{3}\right]$} & 1.594 & 1.434 \\
\hline & \multicolumn{2}{|c|}{$\begin{array}{l}\text { cement content in the concrete } \\
{\left[\mathrm{Mg} / \mathrm{m}^{3}\right]}\end{array}$} & 0.513 & 0.454 \\
\hline \multirow{3}{*}{$\begin{array}{c}\text { Chemical } \\
\text { analysis of the } \\
\text { concrete }\end{array}$} & \multicolumn{2}{|c|}{ the content of $\mathrm{SO}_{3}$ in the calcined cement [\%] } & 1.54 & 1.28 \\
\hline & \multirow{2}{*}{$\begin{array}{l}\text { the content of } \mathrm{CO}_{2} \text { in the } \\
\text { concrete }[\%]\end{array}$} & on average & 1.7 & 1.4 \\
\hline & & from - to & $1.0-2.6$ & $1.0-2.0$ \\
\hline
\end{tabular}

Source: [3]

The obtained results allowed us to draw the conclusions which are presented below, as to the mechanical and physico-chemical properties of the concrete of the bottom plates of the studied foundations.

During the strength tests, the bottom plate of the foundation no. 2 exhibited a higher compressive strength, as compared to the foundation no. 1, namely:

- a higher average strength $\bar{R}$, by approximately $25 \%$,

- a higher guaranteed durability of the concrete $R_{B}^{G}$, by up to circa $40 \%$.

This is confirmed by the $36.6 \%$ lower index of variation and the $9.3 \%$ lower value of standard deviation. 
Moreover, for the concrete of the bottom slab of the foundation no. 2, a higher by as much as $35.7 \%$ value of the static elastic modulus $E_{b}$ was obtained. This result is consistent with the static elastic modulus $E_{b}$ provided in the standard [4] and in the technical literature.

While examining the physical properties, it was found that the higher value of the strength in the case of the bottom plate of the foundation no. 2, is accompanied by the mass absorbability higher by as much as $11.5 \%$, and by approximately $11 \%$ lower bulk density. Additionally, a macroscopic evaluation of the presence of defects and abnormalities (honeycombing, delamination, capillary pores) in the structure of the collected cores was performed. In the case of two samples cut out from the foundation no. 2, larger capillary pores were found in the concrete structure at a depth of 295 and $650 \mathrm{~mm}$ from the outer surface.

While analyzing the composition of the concrete, it was found that the higher porosity and water absorbability of the concrete of the bottom plate of the foundation no. 2 should be explained by the concreting carried out in the summer, when more water was added to the concrete mix. The exothermic reaction of setting and hardening resulted in the occurrence of relatively large capillary pores. On the other hand, in the case of the bottom plate of the foundation no. 1, due to the low sand content, more cement was used. This resulted in the concrete with a lower porosity and absorbability, and higher bulk density, but in lower durability, by approximately $30 \%$.

Chemical tests of the $\mathrm{SO}_{3}$ and $\mathrm{CO}_{2}$ content revealed no threat in this respect. This was due to the location of the foundations below the ground level and protection of their surface with suitable waterproof insulation, and thus protection against the influence of the external environment. In addition, phenolphthalein indicator test was performed on the surface of the collected borehole to determine the advancement of carbonation of the concrete. This test did not show the presence of processes of concrete carbonation.

\section{Results of Non-Destructive Tests of Concrete Durability Distribution}

To study the durability distribution of the concrete in the bottom plates of both foundations, a medium sclerometer of $\mathrm{N}$ type (to estimate the durability at the subsurface, i.e., to a depth of about $10-20 \mathrm{~cm}$ ) and a heavy sclerometer of $\mathrm{M}$ type (to estimate the in-depth durability, i.e, to a depth of about $20-80 \mathrm{~cm}$ ) were used. In the studied research areas, the measurements with both instruments of the values of rebound numbers were carried out at the same time. In total, 7 areas of study for each of the bottom plates were identified, marked in Figure 2 with uppercase letters A-G. When calculating the values of the instruments (for the range of values $L=20-50$ ) regarding the local strength, the scaling curve was used for the sclerometer $\mathrm{N}$, determined in parallel with the destructive studies of the samples cut from the structure. 
On the other hand, for the heavy sclerometer (model $M$ ), the scaling equation was determined using the indirect method. Both dependences met the standard condition of the boundary error value of the approximation function $[5,6]$. The summary of durability values in the research areas, determined with both instruments for the foundations no. 1 and 2 have been presented in Table 3.

The results obtained using both medium sclerometer $(\mathrm{N})$ and the heavy one $(\mathrm{M})$ exhibited higher durability of the concrete of the bottom plate of the foundation no. 2 . Assuming that the heavy sclerometer (M) has a greater ability to identify the durability of the deep-seated area, the results presented in Table 3 gave rise to qualify the concrete class of the bottom plate of the foundation no. 1 to a reliable value of B20, and of the foundation no. 2 to the value of B25 [3]. This is fully consistent with the results of the destructive tests.

Slightly lower values obtained in the tests carried out with the medium sclerometer $(\mathrm{N})$ should be attributed to its greater sensitivity to the roughness of the test surfaces of the foundations and a higher degree of moisture at the surface of the concrete.

Table 3. The characteristics of the concrete durability distributions in the bottom plates of foundations no. 1 and 2, as determined by the non-destructive method with sclerometers $\mathrm{N}$ and $\mathrm{M}$

\begin{tabular}{|c|c|c|c|c|c|c|c|c|}
\hline \multirow{3}{*}{ 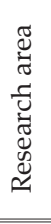 } & \multicolumn{4}{|c|}{ Foundation no. 1} & \multicolumn{4}{|c|}{ Foundation no. 2} \\
\hline & \multicolumn{3}{|c|}{ Distribution parameters $R_{i}$} & \multirow{2}{*}{$\begin{array}{c}\begin{array}{c}\text { Guaranteed } \\
\text { durability }\end{array} \\
R_{B}^{G} \\
{[\mathrm{MPa}]} \\
\end{array}$} & \multicolumn{3}{|c|}{ Distribution parameters $R_{i}$} & \multirow{2}{*}{$\begin{array}{c}\text { Guaranteed } \\
\text { durability } \\
R_{B}^{G} \\
{[\mathrm{MPa}]} \\
\end{array}$} \\
\hline & $\begin{array}{c}\bar{R} \\
{[\mathrm{MPa}]}\end{array}$ & $\begin{array}{c}S_{R} \\
{[\mathrm{MPa}]}\end{array}$ & $\begin{array}{c}\mathrm{Z}_{R} \\
{[\mathrm{MPa}]}\end{array}$ & & $\begin{array}{c}\bar{R} \\
{[\mathrm{MPa}]}\end{array}$ & $\begin{array}{c}S_{R} \\
{[\mathrm{MPa}]}\end{array}$ & $\begin{array}{c}Z_{R} \\
{[\mathrm{MPa}]}\end{array}$ & \\
\hline & \multicolumn{4}{|c|}{ Medium sclerometer $(\mathrm{N})$} & \multicolumn{4}{|c|}{ Medium sclerometer $(\mathrm{N})$} \\
\hline A & 22.0 & 2.9 & 13.4 & 17.2 & 32.8 & 2.1 & 8.5 & 29.3 \\
\hline B & 18.5 & 2.0 & 10.8 & 15.2 & 41.7 & 2.6 & 6.2 & 37.4 \\
\hline C & 26.6 & 3.2 & 11.9 & 21.3 & 39.2 & 2.6 & 6.4 & 34.9 \\
\hline $\mathrm{D}$ & 18.3 & 2.3 & 12.5 & 14.5 & 39.6 & 3.0 & 7.6 & 34.7 \\
\hline E & 20.5 & 3.0 & 14.7 & 16.3 & 33.6 & 3.1 & 9.3 & 28.5 \\
\hline $\mathrm{F}$ & 19.3 & 2.8 & 14.0 & 14.7 & 35.8 & 2.1 & 5.9 & 32.3 \\
\hline \multirow[t]{2}{*}{ G } & - & - & - & - & 33.0 & 2.9 & 8.8 & 28.2 \\
\hline & \multicolumn{4}{|c|}{ Heavy sclerometer (M) } & \multicolumn{4}{|c|}{ Heavy sclerometer $(\mathrm{M})$} \\
\hline A & 26.4 & 4.5 & 17.2 & 19.1 & 33.9 & 3.0 & 9.7 & 29.0 \\
\hline B & 24.3 & 3.9 & 16.1 & 17.8 & 45.2 & 2.9 & 6.4 & 40.0 \\
\hline $\mathrm{C}$ & 24.0 & 2.2 & 9.3 & 20.3 & 43.5 & 2.6 & 6.0 & 39.2 \\
\hline $\mathrm{D}$ & - & - & - & - & 46.8 & 3.2 & 6.8 & 41.5 \\
\hline $\mathrm{E}$ & 25.7 & 3.5 & 13.6 & 20.0 & 34.7 & 2.6 & 7.5 & 30.4 \\
\hline $\mathrm{F}$ & 27.5 & 3.5 & 12.7 & 22.16 & 37.4 & 3.6 & 9.6 & 31.5 \\
\hline G & - & - & - & - & 38.6 & 3.4 & 8.8 & 33.0 \\
\hline
\end{tabular}




\section{Summary}

Reconstruction and modernization of the existing building structures requires the prediction of further sustainability of their structural components. It is essential to determine how long they can continue to be used safely while fulfilling the assumed function.

The article presents a detailed study of the technical condition of the approximately 35-year-old reinforced concrete foundation slabs for turbine sets, conducted in the years 1995-1996. Based on the strength tests of the concrete cores cut out from the bottom plates of the foundations no. 1 and 2, it was found that the resulting compressive strength of the concrete corresponded to at least the B20 and B25 classes, which are required for this type of construction.

According to the currently binding standard PN-EN 206-1:2003 [7], it is equivalent to the C16/20 and C20/25 concrete classes. The results of the physico-chemical tests allowed to conclude that for the conditions which these two bottom plates were placed in (with appropriate waterproof insulation), their durability was not compromised.

The presented results of the research formed the basis for a decision to use both foundations as supports for the framework structure for new turbine sets, thus allowing for further 40 years of their utilization.

Now, after nearly 20 years of use, they show no signs of wear and properly perform their role. Current technical condition of the turbine set foundations confirms that the decision made in the mid-90s was a right one, and the scope of the research which was then carried out can serve as an example of the course of action adopted for similar cases.

\section{References}

[1] Fuksa M., Barycz S.: Opinia w sprawie jakości betonu w masywnych elementach na podstawie badań termicznych fundamentu pod turbozespół 200 MW. Kraków 1963 [unpublished].

[2] Barycz S., Gawlicki M., Mierzwa J.: Badanie techniczne ptyty dolnej fundamentu turbozespołu nr 1 i 2 w elektrowni. AGH, Kraków 1995 and 1996 [unpublished].

[3] Projekt deskowania fundamentu tg $200 \mathrm{MW}$ (obiekt D-6423). Biuro Projektów Energetycznych ENERGOPROJEKT, Warszawa 1960 [technical documentation, unpublished].

[4] PN-88/B-06250 Beton zwykty.

[5] PN-B-06262:1974 Nieniszczace badania konstrukcji z betonu - Metoda sklerometryczna badania wytrzymałości betonu na ściskanie za pomoca młotka Schmidta tури $N$. 
[6] Runkiewicz L., Brunarski L.: Instrukcja stosowania młotków Schmidta do nieniszczacej kontroli jakości betonu w konstrukcji. Instrukcja ITB nr 210, Instytut Techniki Budowlanej, Warszawa 1977.

[7] PN-EN 206-1:2003. Beton. Część 1: Wymagania, właściwości, produkcja i zgodność.

[8] PN-EN 13791:2008. Ocena wytrzymałości betonu na ściskanie w konstrukcjach i prefabrykowanych wyrobach betonowych. 